\title{
Early bilingualism, language transfer, and phonological awareness
}

\author{
LUDO VERHOEVEN \\ Radboud University Nijmegen
}

\author{
ADDRESS FOR CORRESPONDENCE \\ Ludo Verhoeven, Faculty of Social Sciences, Behavioral Science Institute, Radboud University \\ Nijmegen, P.O. Box 9044, Nijmegen 6500 KD, The Netherlands. E-mail: 1.verhoeven@pwo.ru.nl
}

\begin{abstract}
The purpose of the present study was to investigate the relations between early bilingualism and phonological awareness in a sample of 75 Turkish-Dutch bilingual kindergarten children living in The Netherlands. In a longitudinal design, the children's first (L1) and second (L2) language abilities were measured at the beginning and end of kindergarten. At the end of kindergarten, the children's metalinguistic skills within the domain of phonological awareness were also assessed. Linear structural equation modeling was used to examine the types of intralingual (language-specific) and interlingual (language-transfer) processes over time. In addition, just how the patterns of bilingual development related to the children's later phonological awareness was examined. Turkish was found to be the dominant language on both measurement occasions. In addition to the expected longitudinal relations, there was evidence for transfer from L1 to L2. Two interrelated phonological factors emerged: phonotactic awareness and phonemic awareness. Variation in the two types of children's phonological awareness was predicted by both L1 and L2 abilities.
\end{abstract}

In many places throughout the world, children from ethnic minorities are totally immersed in an educational curriculum that involves a second language (L2) with minimal attention to the children's native language. Previous studies of bilingual development suggest that the basic features of the language acquisition process in monolinguals and bilinguals are very similar. Whereas monolingual children confront only one form of linguistic input, bilingual children confront two. The language situation of minority children can thus be characterized as emergent bilingualism with the first language (L1) being built up during the preschool years as the result of linguistic input in L1-speaking homes and the L2 later coming into play via L2 playmates and the school. It can thus be assumed that children receiving L2 input will perform similarly to native speakers on many tests but may nevertheless show some residual asymmetries that reflect the dependence of their L2 knowledge upon their initial L1 knowledge (cf. Hernandez, Li, \& MacWhinney, 2005). The fact that bilingual children deal with two channels of input has also led to the suggestion that bilingual children tend to have higher levels of metalinguistic awareness when compared to their monolingual peers (cf. Bialystok, 1988, 1997). The exact conditions under which language transfer typically occurs (cf. Verhoeven, 1994) and just how particular patterns of bilingual

(C) 2007 Cambridge University Press 0142-7164/07 \$15.00 
development relate to children's metalinguistic awareness are as yet unclear (cf. Hakuta \& Diaz, 1985).

Individual variation can also occur in the L1 and L2 development of ethnic minority children with the notion of interdependence playing a potentially critical role. With respect to the acquisition of academic language skills, Cummins (1983, 1984, 1991) hypothesized the role of interdependence to be as follows: "To the extent that instruction in a certain language is effective in promoting proficiency in that language, transfer of this proficiency to another language will occur, provided there is adequate exposure to that other language (either in the school or environment) and adequate motivation to learn that language." In other words, language transfer can occur not only from L1 to L2 but also from L2 to L1. The interdependence hypothesis further predicts that optimal input in one language leads not only to better skills in that language but also to a deeper conceptual and linguistic proficiency that can clearly facilitate the transfer of various cognitive and academic language skills across languages. Although the surface aspects of linguistic proficiency, such as vocabulary and specific narrative skills, may thus develop separately, an underlying proficiency that is shared across languages can also be assumed.

The competition model of MacWhinney (2004) further predicts that the level of interaction between L1 and L2 may depend upon the degrees of similarity and specific levels of proficiency in the languages (see Hernandez et al., 2005). Transfer may occur when complex linguistic mappings are required by one language but already have a basis in the other language being acquired, for example. Most researchers currently accept the assumption of at least a partially overlapping organization of bilingual memory (French \& Jacquet, 2004) and also the assumption of nonselective linguistic access (i.e., the assumption that linguistic structures in both languages may be accessed simultaneously; de Groot, Delmaar, \& Lupker, 2000; French \& Jacquet, 2004; van Hell \& Dijkstra, 2002). According to the inhibitory control model (Green, 1998), two control mechanisms can be distinguished for bilingual interactive activation, namely a mechanism operating on the input to the bilingual system and a mechanisms operating on the output from the system. Driven by input stimuli, an automatic, bottom-up process modifies the level of activation within the bilingual system whereas an intentional, top-down process responds to signals within the system without modification of the levels of activation. This regulation of the bilingual system provides a good explanation for both the intralingual (i.e., language-specific) and interlingual (i.e., languagetransfer) types of linguistic processes that are known to occur in the bilingual learner and speaker.

Certain aspects of bilingual development may also facilitate the more general cognitive and metalinguistic functioning of children (Hakuta, 1986; Reynolds, 1991). Although the outcomes of studies addressing the cognitive consequences of bilingualism are sometimes subject to debate (see Jarvis, Danks, \& Merriman, 1995), the assumption that bilingual development tends to strengthen children's metalinguistic awareness has received widespread support. Metalinguistic awareness is the ability to explicitate one's (often implicit) knowledge of the structure and functions of language (cf. Karmiloff-Smith, 1997). Bialystok and Ryan (1985) 
have suggested that metalinguistic awareness can be characterized in terms of two components: analysis of knowledge and control of cognitive processing. The analysis component entails the reorganization of linguistic knowledge into abstract categories. The control component entails the intentional selection and application of knowledge to solve metalinguistic problems (see also Bialystok, 1993, 1994).

For the acquisition of literacy, for example, the development of phonological awareness has been shown to be of particular importance (cf. Bialystok, 2002; Snow, Burns, \& Griffin, 1998; Troja, 1999). Phonological awareness requires children to consciously reflect upon the phonological segments of spoken words and manipulate these segments in a systematic manner. Phonological awareness thus depends on a capacity to focus on speech perceptions (Mann, 1991), and this ability can find expression in the division of words into phonemes or syllables, the recognition of rhymes, and alliteration, the use of phonemes and syllables to form words, and the omission, addition, or replacement of phonemes within words. Research shows the development of phonological awareness to progress from the syllable level and the onset-rime level to the more detailed phoneme level (cf. Bradley \& Bryant, 1983; Goswami, 2000). Children find it particularly difficult to make phonemic judgments (i.e., become phonemically aware) because the speech sounds referred to by the letters in most alphabetic writing systems are very abstract and hardly perceivable in spoken language (cf. Nagy \& Scott, 2000; Tunmer, Herriman, \& Nesdale, 1988).

Bilingual children with exposure and access to two sets of linguistic input can be expected to attain relatively high levels of phonological awareness precisely because experience with two language systems and the frequent attention to the phonotactic aspects of language. This claim can be tested in two ways. An indirect test is to show bilingual kindergarten children to have a higher level of phonological awareness than monolingual kindergarten children. In some studies, an advantage to bilingual children in learning about the spoken language was reported (cf. Bruck \& Genessee, 1995; Campbell \& Sais, 1995; Rubin \& Turner, 1989). However, as Bialystok (2002) pointed out, the advantage appears to be mitigated by the age of the children, the nature of the task, and the language pairs in the bilingual mix.

A more direct test of the hypothesis that bilingual development fosters phonological awareness is to examine how particular patterns of L1 and L2 development relate to the phonological awareness of bilingual children. This question has been addressed in only a very few studies. In studies of already literate school-aged children, Bialystok (1988) and Cromdal (1999) showed a high level of bilingualism to be positively related to phonological awareness, but they did not consider the relative contributions of the children's L1 and L2 skills. In a different study, Carlisle, Beeman, Davis, and Spharim (1999) showed levels of L1 and L2 vocabulary and degree of bilingualism to relate significantly to the phonological awareness of bilingual children with below-average reading skills. The fact that all of the aforementioned studies involved children who were already literate nevertheless makes it hard to unravel the causal connections between bilingual development and phonological awareness. 
In the present study, the relations between the bilingual development and phonological awareness of 5-year-old Turkish children attending kindergarten in The Netherlands will be explored. The children are part of a second generation of immigrants to The Netherlands. The initial wave of such immigrants consisted of guest workers who were expected to stay for only a limited period of time. As the period of stay grew longer, the initial pattern of economic migration was gradually replaced by a pattern of social migration involving entire families. A second generation was thus born in the country of residence, and this generation has grown up with considerable ambivalence about whether to stay or return to the country of origin. The language patterns of these immigrant children can be characterized as follows: they primarily live in homes where the mothers are mostly monolingual speakers of the ethnic group language. The early language input to the children is thus restricted to the ethnic group language, and the Dutch language only enters gradually into their lives via Dutch playmates and school attendance (cf. Driessen, van der Slik, \& de Bot, 2002; Extra \& Verhoeven, 1993). In Dutch kindergarten, the focus is on the development of oral language skills with a little attention to the promotion of phonological awareness. For bilingual children, their instruction is L2 based right from the beginning.

A longitudinal study was conducted to explore the relations between the bilingual development and phonological awareness of the minority Turkish children attending kindergarten in The Netherlands. We were particularly interested in the children's phonological awareness, as this is highly relevant for the children's literacy development. The answers to the following research questions were sought for this purpose.

1. How do L1 and L2 skills of the Turkish children attending kindergarten in The Netherlands develop between 5 and 6 years of age?

2. Is there empirical evidence for interdependence in the development of the L1 and L2 skills of the Turkish children?

3. To what extent do individual differences in the bilingual development of the Turkish children relate to their phonological awareness?

\section{METHOD}

\section{Participants}

In the present study, the patterns of L1 and L2 development for 75 Turkish children born and living in The Netherlands were examined. Turks form the largest minority group in The Netherlands. In 2005 there were 360,000 Turkish people (CBS, 2005) with some 57,000 Turkish children in Dutch elementary school, which is about $4 \%$ of the elementary school population. The children for the present study were recruited from 27 kindergarten classrooms in nine fairly large cities distributed throughout the country. The age of the kindergarten children varied from 5 years, 1 month to 5 years, 9 months, with a mean of 5 years, 5 months. The children's L1 and L2 proficiencies were tested at both the beginning and end of the school year. Their phonological awareness was also tested at the end of the school year. 
Verhoeven: Bilingualism and phonological awareness

\section{Language proficiency tests}

Assuming a hierarchical language structure, separate tasks were administered to measure the phonological, lexical, morphosyntactic, and textual abilities of the children. The L1 and L2 tests were as similar as possible, and administered by a bilingual research assistant who presented the instructions in both the L1 and L2. At the lexical level, vocabulary measures were administered for not only content words but also for function words (i.e., color names, quantifiers, temporal terms, and spatial terms).

Auditory Discrimination Test. The Auditory Discrimination Test measures perception of minimal phonemic differences in monosyllabic words in the languages under consideration ( 25 items). The children are asked to repeat minimal word pairs that thus differ with respect to only one phoneme. Examples for Dutch are beer-peer (bear-pear) and pit-pet (pit-pet). For Turkish, the selection of minimal pairs was based on Clements and Sezer (1982). The total test score is the number of word pairs reproduced correctly.

Receptive and Productive Vocabulary Tests. In the Receptive Vocabulary Test the comprehension of content words is assessed (40 nouns, 20 verbs). The words are spoken as the child is shown four pictures, with one of the pictures representing the correct meaning of the word. A total of 60 items with increasing difficulty is presented; when the child does not respond correctly to five consecutive items, the task is ended. The total test score is the number of items responded to correctly.

The Productive Vocabulary Test measures the production of content words (30 nouns, 10 verbs). Pictures of objects and actions are presented, and the child is asked to describe each picture. A total of 40 items with increasing difficulty is presented; when the child does not respond correctly to five consecutive items, testing is terminated. The total test score is the number of pictures described correctly.

To obtain more or less equivalent vocabulary measures for Turkish and Dutch, the following procedure was followed. A corpus of 7000 Dutch words was evaluated by 200 teachers using the criterion that the teachers thought a particular word would be understood by a 6-year-old native speaker of Dutch. The list of words was next ordered according to teacher agreement, with almost $100 \%$ of the teachers thus agreeing that the first words would be understood and only $25 \%$ of the teachers agreeing that the last words would be understood. After this, 1 out of every 20 successive words on the list was selected for inclusion in a shorter list. Culture-specific words were excluded from the short list (e.g., kerk [church] and varken [pork] for Dutch). The Turkish equivalents for the words were next sought. Words that could only be expressed by a compound or three or more words were eliminated from the list. A list of 200 words was the result. The minority language list was then presented to four teachers who were native speakers of Turkish but working in a Dutch school with the request that they indicate those words that they thought a 6-year-old native Turkish child living in The Netherlands would understand. After the native Turkish-speaking teachers had worked through the list, the words were ordered according to their agreement ratings. The interrater 
reliability for the final list of words turned out to be high (greater than .90), which means that the lists can be considered unbiased with regard to culture. Two sets of words were then established for each language: one with 60 words for receptive vocabulary testing and one with 40 words for productive vocabulary testing.

Function Word Comprehension Test. The Function Word Comprehension Test assesses the children's comprehension of references to concepts in the following categories: color ( 15 items), shape ( 15 items), quantity ( 15 items), space ( 10 items), and cause-effect (10 items). These references are considered "linguistic universals" or linguistic features that are common to all languages and thus assumed to reflect some innate predispositions for perception and cognition (cf. Clark \& Clark, 1977). The children are presented three pictures and orally read a stimulus sentence that corresponds to one of the pictures. The total test score is the number of correctly selected pictures.

Sentence Imitation Test. The Sentence Imitation Test involves the reproduction of 40 critical morphosyntactic features embedded in orally presented sentences. A total of 20 sentences containing a rich variety of grammatical morphemes and syntactic structures is presented per language. The mean sentence length and mean number of nominal and verbal phrases was held constant across the languages. The child is asked to reproduce a sentence as soon as it has been spoken. If the child does not respond, the sentence is repeated once. The morphosyntactic features under investigation are function words and word order characteristics. For Turkish, the selection of morphosyntactic devices was based on Lewis (1986) for Dutch, the selection was based on Koster (1975). The total number of correctly reproduced features constitutes the child's test score.

Story Comprehension Test. The comprehension of explicit information (10 items) and implicit information (10 items) for orally presented stories is assessed in this test. Similar story plots were developed for the Dutch and Turkish languages. Each test involved four short texts. After a text was read by an experimenter, five questions were posed with regard to information explicitly presented in the text and information implicitly presented. The total test score is the number of questions responded to correctly by the child.

Cronbach alpha coefficients were calculated to estimate the internal consistency of the L1 and L2 tests. All of the tests showed a reasonable degree of internal consistency. In all cases, the value of the Cronbach $\alpha$ was .85 or higher.

\section{Phonological awareness tests}

To assess the children's phonological awareness, four tests with Dutch items were used (Verhoeven \& van Kuyk, 1991). Just as for the other language tests, the tests of phonological awareness were administered by a bilingual research assistant who used both the L1 and L2 to instruct the child. The tests were as follows.

Rhyming. The Rhyming Test involves 10 test items. For each item, the child hears a word and is shown four pictures, with one of the pictures depicting a word 
that rhymes with the presented word. The child must point to the picture depicting the rhyming word. Distracters include semantically related pictures.

Word objectification. The Word Objectification Test involves 10 test items. For each item, a word pair is presented orally and the child is asked to judge which word is longest. For most of the pairs, the longer word refers to a concept with a smaller size (e.g., cat-caterpillar).

Phoneme segmentation. In the Phoneme Segmentation Test the child is asked to analyze words into their phonemes. The test involves 10 words with a length that increases from two to five phonemes.

Word blending. In the Word Blending Test the child has to synthesize words by combining their separate phonemes. The test involves 10 words with a length that increases from two to five phonemes.

For the four tests of phonological awareness, the Cronbach $\alpha$ s all had a value of .82 or greater. This shows the internal consistency of the tests is reasonable.

\section{Procedure}

A series of analyses of variance (ANOVAs), using time (beginning of kindergarten, end of kindergarten) as a repeated measure and language (L1, L2) as a withinsubject factor, examined the patterns of language development. To explore the relations between level of bilingual proficiency and phonological awareness, those children with a high proficiency in both L1 and L2 (factor scores in L1 and L2 above average) were compared to those children with a high level of proficiency in only one of the languages (factor score in L1 or L2 above average) and those children with a low proficiency in both of the languages (factor scores in L1 and L2 below average).

A series of LISREL analyses (Version 8; Jöreskog \& Sörbom, 1996) were conducted to explore the relationships between the children's L1 and L2 abilities over time and the extent to which the development of word decoding can be explained by various child, family, and institutional characteristics. With the purpose of data reduction, the factor scores for the children's L1 and L2 abilities on the two measurement occasions were entered into the structural models. In the design of the structural models, both cross-sectional and longitudinal effects were included. The factor Time was considered fixed in the sense that variables later in time cannot be presumed to influence variables earlier in time. Estimation and testing were conducted using maximum likelihood analyses. The fit of the model was evaluated in terms of the chi-square and a number of goodness of fit indices: goodness of fit index (GFI), adjusted GFI (AGFI), normed FI (NFI), and root mean square error of approximation (RMSEA). According to Jaccard and Wan (1996) and $\mathrm{Hu}$ and Bentler (1999), fit is satisfactory whenever the GFI, AGFI, and NFI approximate are $>.90$ and the RMSEA is $<.08$. Given that the significance of the chi-square test is known to depend on sample size, the chi-square value was not taken to be decisive. 
Verhoeven: Bilingualism and phonological awareness

Table 1. Means (standard deviations) for the first language Turkish and second language Dutch proficiency tests administered on two measurement occasions

\begin{tabular}{lrrrrr}
\hline \hline & \multicolumn{2}{c}{ Beginning of Kindergarten } & & \multicolumn{2}{c}{ End of Kindergarten } \\
\cline { 2 - 3 } \cline { 6 - 6 } & Turkish & Dutch & & Turkish & Dutch \\
\hline Auditory discrimination (25) & $22.08(3.32)$ & $16.00(4.21)$ & & $23.36(1.96)$ & $18.89(3.21)$ \\
Receptive vocabulary (60) & $38.73(8.41)$ & $22.24(9.63)$ & & $44.37(6.06)$ & $34.01(8.38)$ \\
Productive vocabulary (40) & $20.84(5.23)$ & $5.99(3.60)$ & & $23.43(5.47)$ & $10.91(4.25)$ \\
Function word & & & & & \\
$\quad$ comprehension (65) & $41.80(8.35)$ & $35.32(8.49)$ & & $50.44(5.83)$ & $47.75(6.53)$ \\
Sentence repetition (40) & $23.41(9.07)$ & $10.63(7.71)$ & & $26.93(6.17)$ & $18.31(7.57)$ \\
Story comprehension (20) & $13.15(3.95)$ & $5.35(4.74)$ & & $16.47(2.82)$ & $11.17(4.27)$ \\
\hline \hline
\end{tabular}

\section{RESULTS}

\section{Patterns of bilingual development}

In Table 1 the means and standard deviations for the L1 and L2 proficiency of the children on the two measurement occasions are presented. Turkish can be seen to predominate over Dutch on all of the tests, although the L1 versus L2 differences decline over time. The differences between the two languages tend to be relatively large for productive vocabulary, sentence imitation, and story comprehension on each of the two measurement occasions.

The results of the repeated measures ANOVA with language as a within-subject factor for auditory discrimination showed effects of language, $F(1,74)=204.64$, $p<.001$, time, $F(1,74)=49.01, p<.001$, and their interaction, $F(1,74)=7.36$, $p<.01$. The results for receptive vocabulary showed effects of language, $F$ (1, $74)=169.51, p<.001$, time, $F(1,74)=149.91, p<.001$, and their interaction, $F(1,74)=24.56, p<.001$. The results for productive vocabulary showed effects of language, $F(1,74)=373.99, p<.001$, time, $F(1,74)=93.93, p<.001$, and their interaction, $F(1,74)=12.91, p<.01$. The results for function word comprehension showed effects of language, $F(1,74)=41.15, p<.001$, time, $F(1,74)=342.35, p<.001$, and their interaction, $F(1,74)=15.62, p<.001$. The results for sentence imitation showed effects of language, $F(1,74)=146.52$, $p<.001$, time, $F(1,74)=84.34, p<.001$, and their interaction, $F(1,74)=$ $12.53, p<.01$. The results for text comprehension showed effects of language, $F(1,74)=223.75, p<.001$, time, $F(1,74)=176.93, p<.001$, and their interaction, $F(1,74)=17.98, p<.001$. These results point to the fact that generally children obtain higher scores in Turkish compared to Dutch and make significant progression in the two languages, with the differences in Turkish and Dutch language scores becoming smaller with progression of time.

\section{Interdependencies between $L 1$ and $L 2$ development}

Factor analyses on the L1 and L2 proficiency scores of the children on the two measurement occasions yielded a one-factor solution for all of the tests. In 
Table 2. Factor loadings for the tests of Turkish and Dutch language proficiency administered on two occasions

\begin{tabular}{|c|c|c|c|c|}
\hline & \multicolumn{2}{|c|}{$\begin{array}{l}\text { Beginning of } \\
\text { Kindergarten }\end{array}$} & \multicolumn{2}{|c|}{$\begin{array}{c}\text { End of } \\
\text { Kindergarten }\end{array}$} \\
\hline & Turkish & Dutch & Turkish & Dutch \\
\hline Auditory discrimination & .19 & .42 & .35 & .52 \\
\hline Receptive vocabulary & .77 & .79 & .74 & .73 \\
\hline Productive vocabulary & .77 & .78 & .70 & .69 \\
\hline \multicolumn{5}{|l|}{ Function word } \\
\hline comprehension & .82 & .83 & .83 & .78 \\
\hline Sentence imitation & .81 & .79 & .71 & .81 \\
\hline Text comprehension & .83 & .75 & .75 & .66 \\
\hline
\end{tabular}

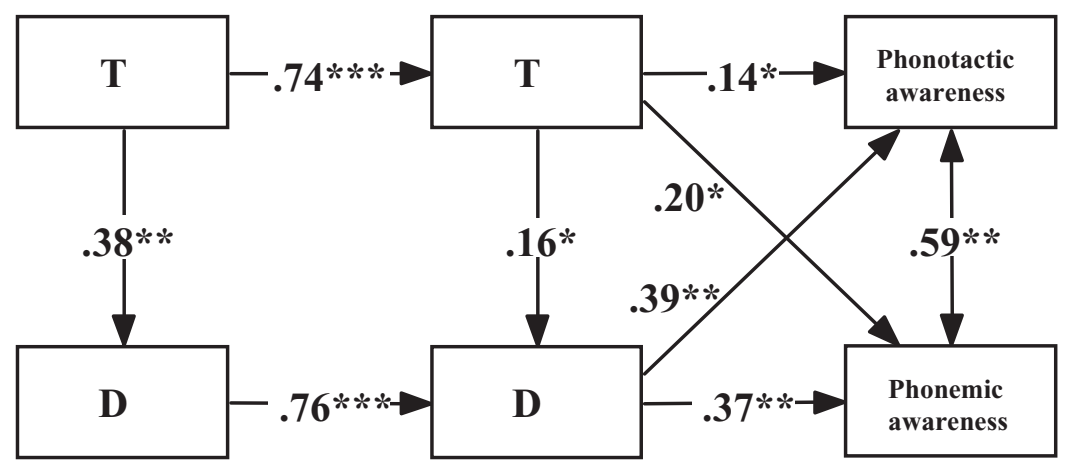

Figure 1. Structural model of relations between Turkish (T1, T2) and Dutch (D1, D2) development and phonological awareness.

Table 2, the amount of variance explained by the first factor is reported for each test. It can be seen that all tests show high loadings on the Turkish and Dutch language factors. The relatively low loadings of the Auditory Discrimination Test might be due to ceiling effects.

The left part of Figure 1 presents the results of the linear structural analysis on the factor scores for the L1 and L2 tests across the two measurement occasions. The boxes stand for the factor scores of L1 Turkish and L2 Dutch on the two moments of measurement, and the arrows depict both the direction and the strengths of the relationships between these factor scores. The results show strong longitudinal relations per language and moderate interrelations between the L1 and L2 levels of proficiency per measurement occasion. The fit of this part of the model was good with a nonsignificant chi-square value, high fit indices and a low error index: $\chi^{2}=8.203, d f=8, p=.414, \mathrm{GFI}=0.964, \mathrm{AGFI}=0.905, \mathrm{NFI}=0.971$, RMSEA $=0.019$. 
Verhoeven: Bilingualism and phonological awareness

Table 3. Means (standard deviations) of the total sample and the subsamples of children with high versus low levels of first language (L1) and second language (L2) for the tests of phonological awareness in Dutch

\begin{tabular}{lccccc}
\hline \hline & $\begin{array}{c}\text { Total } \\
\text { Sample }\end{array}$ & $\begin{array}{c}\text { High } \\
\text { L1/L2 }\end{array}$ & $\begin{array}{c}\text { High L1/ } \\
\text { Low L2 }\end{array}$ & $\begin{array}{c}\text { Low L1/ } \\
\text { High L2 }\end{array}$ & Low L1/L2 \\
\hline $\begin{array}{l}\text { Word } \\
\quad \text { objectification }\end{array}$ & $6.07(3.17)$ & $7.30(2.58)$ & $5.33(3.13)$ & $5.92(2.78)$ & $4.67(1.92)$ \\
$\begin{array}{l}\text { Rhyme } \\
\text { Phoneme }\end{array}$ & $5.17(3.53)$ & $6.70(3.61)$ & $4.42(3.51)$ & $4.94(3.07)$ & $4.38(3.39)$ \\
$\quad$ segmentation & $2.74(4.59)$ & $4.84(3.78)$ & $2.05(3.47)$ & $1.83(3.53)$ & $1.25(2.01)$ \\
Word blending & $5.02(6.03)$ & $7.65(4.07)$ & $4.85(3.61)$ & $3.75(3.86)$ & $1.75(1.76)$ \\
\hline \hline
\end{tabular}

\section{Bilingual development and phonological awareness}

Table 3 presents the means and standard deviations for the tests of phonological awareness. As can be seen, the children experienced considerable difficulty with the phoneme segmentation task.

The mean scores on the four tests of phonological awareness in Dutch were next computed for those children with high versus low language scores (i.e., abovevs. below-average factor scores at the end of kindergarten). Table 3 provides the results for those children scoring high on both the Turkish (L1) and Dutch (L2) language tests, high on the L1 tests but low on the L2 tests, low on the L1 tests but high on the L 2 tests, and low on both the L1 and L 2 tests. In all cases, those children scoring high on both the L1 and L2 tests also produced the highest scores on the four tests of phonological awareness. The results of the analyses of variance further show the differences between the four groups of children to be statistically significant for the Word Objectification Test, $F(3,73)=3.58, p<.01$, the Phoneme Segmentation Test, $F(3,73)=3.40, p<.01$, and the Word Blending Test, $F(3,73)=3.13, p<.05$. Only a trend toward significance is observed for the rhyme test $(p<.10)$. Subsequent post-ANOVA contrast tests show those children with both high L1 and high L2 test scores to score significantly higher on the four phonological tests when compared to all other children $(p<.05)$.

The factor analyses on the children's phonological awareness test scores yielded a two-factor solution. The Rhyming and Word Objectification Tests loaded on the first factor whereas the Phoneme Segmentation and Word Blending Tests loaded on the second factor (see Table 4). The first factor was therefore called "phonotactic awareness" and the second factor "phonemic awareness."

The outcomes of the structural equation analyses conducted to explore the relations between the children's L1 and L2 development, on the one hand, and their phonological awareness, on the other hand, are also portrayed in Figure 1. The boxes stand for the factor scores of L1 Turkish and L2 Dutch and of phonological and phonemic awareness on the two moments of measurement, and the arrows depict both the direction and the strengths of the relationships between these factor scores. The fit of this complete model was found to be satisfactory with a nonsignificant chi-square value, substantial to high fit indices and a low 
Verhoeven: Bilingualism and phonological awareness

Table 4. Factor loadings for four tests of phonological awareness administered at the end of kindergarten

\begin{tabular}{lcc}
\hline \hline & Phonotactic Awareness & Phonemic Awareness \\
\hline Word objectification & $\mathbf{. 7 1}$ & .30 \\
Rhyme & $\mathbf{. 8 6}$ & .09 \\
Phoneme segmentation & .20 & $\mathbf{. 8 4}$ \\
Word blending & .34 & $\mathbf{. 7 9}$ \\
\hline \hline
\end{tabular}

Note: Bold values indicate factor loadings.

error index: $\chi^{2}=51.383, d f=37, p=.060, \mathrm{GFI}=.906$, AGFI $=.803, \mathrm{NFI}=$ .875 , RMSEA $=.072$. As can be seen, the patterns of $\mathrm{L} 1$ and $\mathrm{L} 2$ development both significantly relate to the children's phonological and phonemic awareness. The predictive power of Dutch language proficiency at moment 2 (D2) can be qualified as substantial and that of Turkish language proficiency at the same moment (T2) as more modest.

\section{CONCLUSIONS AND DISCUSSION}

Several conclusions can be drawn on the basis of the present results. First, the data show both the L1 and L2 proficiency of the children studied here to progress between the ages of 5 and 6 years. From the very beginning to the end of kindergarten, however, Turkish tends to predominate. Only partial evidence for a language shift is found. It can thus be concluded that the kindergarten teachers only partly succeed at bridging the gap in the L1 and L2 proficiencies of the young children in their care. The teachers were not very successful for productive vocabulary skills and productive morphosyntactic skills, which suggests that the school environment is not capable of bringing the more complex L2 skills up to the level of the children's simpler L2 receptive skills.

The present results also show the patterns of development for the L1 and L2 abilities of the children to be related. Evidence for Cummins' interdependence hypothesis is thus provided by the present results. The language situation of the Turkish children in our study can best be characterized as "emergent bilingualism." The L1 is built up in the largely L1-speaking homes, and the L2 only later comes into play via L2-speaking playmates and the school. Strong longitudinal relations for both the children's L1 and L2 development were detected along with a significant amount of transfer from L1 to L2. That is, the bilingual children basically perform like native speakers on many tasks but nevertheless show some residual asymmetries, which show their L2 skills to still depend on their L1 skills at times (cf. Hernandez et al., 2005).

The present results further show the children's bilingual development to relate to their phonological awareness at the end of kindergarten. Those children who showed relatively high levels of both L1 and L2 proficiency also produced relatively higher scores on the four tests of phonological awareness. This effect was most striking for the tests of phonemic awareness, particularly phoneme segmentation. Thus, it can be concluded that the level of bilingual development 
appears to have an impact on the development of phonological awareness, and that the effects are strongest for the tasks that made greatest demands on phonological awareness.

In a similar vein, our structural equation modeling of children's bilingual development during kindergarten shows both L1 and L2 to independently predict their phonotactic and phonemic awareness. It is interesting to note that at the end of kindergarten the children's L2 knowledge is found to be a stronger predictor of the two types of phonological awareness than their L1 knowledge. Neither the children's L1 knowledge at the beginning of kindergarten nor their L2 knowledge at the beginning of kindergarten, however, contribute to the prediction of their phonological awareness at the end of kindergarten, which suggests that the prediction of phonological awareness only emerges during the course of kindergarten.

The notions of language interdependence, emergent bilingualism, and phonological awareness have important implications for the education of minority children. Given the close links between phonological awareness and emerging literacy, policy makers should take the findings of linguistic interdependence seriously into consideration and provide support for bilingual programs at the preschool and kindergarten levels. Bilingual education can stimulate children's development in at least two ways. Attention to the native language of minority children may directly enhance their self-respect by showing them that the language in which they have invested their initial years is respected by the school. Sufficient support for the L1s of minority children may also indirectly enhance their cognitive/academic skills in not only the particular L1 but also in the L2.

With respect to the minority children's L2 development, our finding that the development of productive language skills tends to lag behind the development of receptive language skills merits attention. Language learning has been found to be a passive process in many schools today (cf. Verhoeven, 1996). Students are often given materials that require a largely passive manner of processing. Examples are collections of texts for reading, workbooks, or worksheets based on a single educational route or a single solution, which can reinforce a passive orientation on the part of students. The learning of communicative skills involving spoken and written language requires active student participation, and research has shown that students also achieve better results when they are more actively involved in the advanced language learning process (cf. Bruner, 1986; Snow, 1991).

Although the results of the present study provide clear evidence of a relation between bilingual development and phonological awareness, a few words of caution are in order. The number of informants in the present study was limited. To arrive at some more definite answers to our questions, replication should be undertaken with larger groups of informants. Furthermore, the present study involved just one minority language. To be able to generalize, various ethnic communities and minority languages should be involved. Comparison of the patterns of bilingual development to patterns of monolingual development in otherwise comparable peer groups is also recommended (cf. Oller \& Eilers, 2002; Pearson, Fernandez, \& Oller, 1993). Furthermore, in the present study we used phonological awareness tests in Dutch, the language of beginning literacy instruction, only. To get better insight into the processes of cross-language transfer of phonological awareness, the instrumentation of phonological awareness in both L1 and L2 can be 
recommended in future studies. The links between bilingual development and phonological awareness may also be extended to other domains of metalinguistic awareness and examined across the elementary school years. Only in longitudinal studies with bilingual variability considered in connection to the children's metalinguistic awareness and literacy can the significance of bilingualism for academic achievement be fully established (cf. Bialystok \& Herman, 1999).

A final concern is to what extent the present findings can be generalized to other countries in the world. Obvious similarities with regard to the demographic characteristics of the ethnic minorities involved can be demonstrated cross-nationally. In many countries, for example, minorities have a low socioeconomic status, a low level of education, low levels of professional training, and major unemployment. Many ethnic minority languages also have a low status. Taken together, these factors show minority children in a variety of migration contexts to typically acquire a second (or third) language in a so-called submersion environment, although this need not be the case. Given similar demographic, language, and submersion factors, thus, the predictors of early bilingual development can presumably be generalized from one situation to the other (see also Cummins, 1989, on this point). To attain a more complete understanding of the complex relations between bilingual development and metalinguistic awareness, however, a clearly cross-linguistic and cross-cultural research approach appears to be necessary. Naturalistic studies such as the present one certainly constitute a first step toward a better understanding of emergent bilingualism and children's metalinguistic awareness within a migration context, but comparative studies in which the relevant relations are systematically explored should also be undertaken (cf. Genesee \& Gandara, 1999).

\section{REFERENCES}

Bialystok, E. (1988). Levels of bilingualism and levels of linguistic awareness. Developmental Psychology, 24, 560-567.

Bialystok, E. (1993). Metalinguistic awareness: The development of children's representations of language. In C. Pratt \& A. F. Garton (Eds.), Systems of representation in children (pp. 211233). New York: Wiley.

Bialystok, E. (1994). Analysis and control in the development of second language proficiency. Studies in Second Language Acquisition, 16, 157-168.

Bialystok, E. (1997). Effects of bilingualism and biliteracy on children's emerging concepts of print. Developmental Psychology, 33, 429-440.

Bialystok, E. (2002). Acquisition of literacy in bilingual children: A framework for research. Language Learning, 52, 159-199.

Bialystok, E., \& Herman, J. (1999). Does bilingualism matter for early literacy? Bilingualism: Language and Cognition, 2, 35-44.

Bialystok, E., \& Ryan, E. B. (1985). Metacognitive framework for the development of first and second language skills. In D. L. Forrest-Pressley, G. E. MacKinnon, \& T. G. Waller (Eds.), Metacognition, cognition and human performance (pp. 207-252). New York: Academic Press.

Bradley, L., \& Bryant, P. E. (1983). Categorizing sounds and learning to read-A causal connection. Nature, 301, 419-422.

Bruck, M., \& Genesee, F. (1995). Phonological awareness in young second language learners. Journal of Child Language, 22, 307-324.

Bruner, J. (1986). Actual minds, possible worlds. Cambridge, MA: Harvard University Press.

Campbell, R., \& Sais, E. (1995). Accelerated metalinguistic (phonological) awareness in bilingual children. British Journal of Developmental Psychology, 13, 61-68. 
Verhoeven: Bilingualism and phonological awareness

Carlisle, J. F., Beeman, M. M., Davis, L. H., \& Spharim, G. (1999). Relationship of metalinguistic capabilities and reading achievement for children who are becoming bilingual. Applied Psycholinguistics, 20, 459-478.

CBS. (2005). Allochtonen in Nederland 2005 [Non-indigenous communities in The Netherlands 2005]. Voorburg, The Netherlands: Author.

Clark, H. H., \& Clark, E. V. (1977). Psychology and language. New York: Harcourt, Brace, Jovanovich.

Clements, G. N., \& Sezer, E. (1982). Vowel and consonant disharmony in Turkish. In H. van der Hulst \& N. Smith (Eds.), The structure of phonological representations (Part II, pp. 213-256). Dordrecht: Foris.

Cromdal, J. (1999). Childhood bilingualism and metalinguistic skills: Analysis and control in young Swedish-English bilinguals. Applied Psycholinguistics, 20, 1-20.

Cummins, J. (1983). Heritage language education: A literature review. Toronto: Ministry of Education.

Cummins, J. (1984). Wanted: A theoretical framework for relating language proficiency to academic achievement among bilingual students. In C. Rivera (Ed.), Language proficiency and academic achievement (pp. 2-19). Clevedon: Multilingual Matters.

Cummins, J. (1989). Language and literacy acquisition in bilingual contexts. Journal of Multilingual and Multicultural Development, 10, 17-31.

Cummins, J. (1991). Conversational and academic language proficiency in bilingual contexts. AILA Review, 8, 75-89.

De Groot, A. M. B., Delmaar, P., \& Lupker, S. J. (2000). The processing of interlexical homographs in translation recognition and lexical decision: Support for nonselective access to bilingual memory. The Quarterly Journal of Experimental Psychology, 53A, 397-428.

Driessen, G., van der Slik, F., \& de Bot, K. (2002). Home language and language proficiency: A largescale longitudinal study in Dutch primary schools. Journal of Multilingual and Multicultural Development 20, 175-194.

Extra, G., \& Verhoeven, L. (1993). Community languages in The Netherlands. Lisse, Switzerland: Swets \& Zeitlinger.

French, R. M., \& Jacquet, M. (2004). Understanding bilingual memory: Models and data. Trends in Cognitive Science, 8, 87-93.

Genesee, F., \& Gándara, P. (1999). Bilingual education programs: A cross-national perspective. Journal of Social Issues, 55, 665-685.

Goswami, U. (2000). Phonological and lexical processes. In M. L. Kamil, P. B. Rosenthal, P. D. Pearson, \& R. Barr (Eds.), Handbook of reading research (Vol. 3, pp. 251-268). Mahwah, NJ: Erlbaum.

Green, D. W. (1998). Mental control of the bilingual lexico-semantic system. Bilingualism, Language and Cognition, 1, 67-81.

Hakuta, K. (1986). Mirror of language: The debate on bilingualism. New York: Basic Books.

Hakuta, K., \& R. M. Diaz (1985). The relationship between degree of bilingualism and cognitive ability: A critical discussion and some new longitudinal data. In K. D. Nelson (Ed.), Children's language (pp. 319-344). Hillsdale, NJ: Erlbaum.

Hernandez, A., Li, P., \& MacWhinney, B. (2005). The emergence of competing modules in bilingualism. Trends in Cognitive Sciences, 9, 220-225.

Hu, L., \& Bentler, P. M. (1999). Cutoff criteria for fit indices in covariance structure analysis: Conventional criteria versus alternatives. Structural Equation Modeling, 6, 1-55.

Jaccard, J., \& Wan, C. K. (1996). LISREL Approaches to Interaction Effects in Multiple Regression. Thousand Oaks, CA: Sage.

Jarvis, L. H., Danks, J. H., \& Merriman, W. E. (1995). The effect of bilingualism on cognitive ability: Is it second language dependent or cognitive-level dependent? Applied Psycholinguistics, 16, 293-308.

Jöreskog, K. G., \& Sörbom, D. (1996). LISREL 8. User's reference guide. Chicago: Scientific Software International, Inc.

Karmiloff-Smith, A. (1997). Beyond modularity. Cambridge, MA: MIT Press.

Koster, J. (1975). Dutch as an SOV Language. Linguistic Analysis, 1, 111-136.

Lewis, G. L. (1986). Turkish grammar. Oxford: Clarendon Press.

MacWhinney, B. (2004). A unified model of language acquisition. In J. F. Kroll \& A. M. B. de Groot (Eds.), Handbook of bilingualism: Psycholinguistic approaches (pp. 49-67). Oxford: Oxford University Press. 
Verhoeven: Bilingualism and phonological awareness

Mann, V. A. (1991). Phonological abilities: Effective predictors of future reading ability. In L. Rieben \& C. A. Perfetti (Eds.), Learning to read (pp. 121-133). Hillsdale, NJ: Erlbaum.

Nagy, W. E., \& Scott, J. A. (2000). Vocabulary processes. In M. L. Kamil (Ed.), Handbook of Reading Research (Vol. 111, pp. 269-284). Mahwah, NJ: Erlbaum.

Oller, K., \& Eilers, R. (Eds.). (2002). Language and literacy in bilingual children. Clevedon: Multilingual Matters.

Pearson, B. Z., Fernandez, M. C., \& Oller, D. K. (1993). Lexical development in bilingual infants and toddlers: Comparison to monolingual norms. Language Learning, 43, 93-120.

Reynolds, A. G. (1991). The cognitive consequence of bilingualism. In A. G. Reynolds (Ed.), Bilingualism, multiculturalism, and second language learning (pp. 145-182). Hillsdale, NJ: Erlbaum.

Rubin, H., \& Turner, A. (1989). Phonological awareness in young second language learner. Journal of Child Language, 22, 307-324.

Snow, C. (1991). The theoretical basis for relationships between language and literacy in development. Journal of Research in Childhood Education, 6, 5-10.

Snow, C. E., Burns, M. S., \& Griffin, P. (1998). Preventing reading difficulties in young children. Washington, DC: National Academy Press.

Troia, G. A. (1999). Phonological awareness intervention research: A critical review of the experimental methodology. Reading Research Quarterly, 34, 28-52.

Tunmer, W. E., Herriman, M. L., \& Nesdale, A. R. (1988). Metalinguistic abilities and beginning reading. Reading Research Quarterly, 23, 134-155.

Van Hell, J. G., \& Dijkstra, T. (2002). Foreign language knowledge can influence native language performance in exclusively native contexts. Psychonomic Bulletin and Review, 9, 780-789.

Verhoeven, L. (1994). Transfer in bilingual development. Language Learning, 44, 381-415.

Verhoeven, L., \& Van Kuyk, J. J. (1991). Peiling van conceptuele en metalinguïstische kennis bij de aanvang van het basisonderwijs [Assessment of conceptual and phonological knowledge at the entrance of kindergarten]. Pedagogische Studiën, 68, 415-425. 